\title{
Estimasi Harga Jual Mobil Bekas Menggunakan Metode Regresi Linier Berganda
}

\author{
Evi Dewi Sri Mulyani'), Firham Mulady'), Dendi Ramadhan ${ }^{3)}$, Ari Ariyantono ${ }^{4)}$, Dikri Ramdani ${ }^{5)}$, \\ Robi Wahyundana'), M. Gilang ${ }^{7}$ \\ STMIK TASIKMALAYA, Program Studi Teknik Informatika \\ Email: ${ }_{1}$ eviajadech@gmail.com, ${ }^{2}$ firham.mulady21@gmail.com, ${ }^{3}$ dendir@gmail.com, \\ 4ariyanono88@gmail.com, ${ }^{5}$ dikriramdani@gmail.com, ${ }^{6}$ robiwahyundana@gmail.com, \\ 7mgilang@gmail.com
}

\begin{abstract}
Abstrak
Meningkatnya jumlah produksi mobil baru dan munculnya berbagai model mobil baru berdampak dengan melimpahnya mobil bekas atau dengan sebutan mobil second, yang dapat membuat masyarakat tertarik menjadi pengusaha dalam bisnis jual beli mobil bekas. Dengan disertai pajak yang lebih terjangkau dan proses peralihan kepemilikan yang tidak sulit menjadikan bisnis ini menjadi lebih menjanjikan di masyarakat. Mobil bekas memiliki harga jual yang menurun secara periodik, jadi harga jual suatu mobil bekas pada tahun yang sedang berjalan lebih rendah dari harga Oleh karena itu estimasi harga jual mobil bekas sangat diperlukan dalam membantu pengusaha untuk membantu penjualan mobil bekas dengan harga jual secara periodik. Dengan membuat estimasi harga jual mobil bekas menggunakan metode regresi linier berganda ini berdasarkan variabel merk, harga beli, tahun keluar (tahun pembuatan atau tahun perakitan), dan kondisi mobil ini telah mampu menghasilkan nilai perkiraan harga jual mobil bekas secara periodik dan pengujian dari hasil estimasi dengan hasil real sebesar $2,65 \%$.
\end{abstract}

Kata Kunci-3-5 Data Mining, Estimasi Harga, Linier Berganda.

\begin{abstract}
The increasing number of new car production and the emergence of various new car models have an impact with the abundance of used cars or as a second car, which can make people interested in becoming entrepreneurs in the business of buying and selling used cars. With a more affordable tax and a process of ownership transfer that is not difficult to make this business more promising in the community. Used cars have a selling price that decreases periodically, so the selling price of a used car in the current year is lower than the price. Therefore, the estimated selling price of used cars is very necessary in helping entrepreneurs to help sell used cars with periodic selling prices. By estimating the selling price of used cars using this multiple linear regression method based on brand variable, purchase price, year of exit (year of manufacture or year of assembly), and the condition of this car has been able to produce an estimated value of used car selling prices periodically and testing the estimated results with real results of $2.65 \%$.
\end{abstract}

Keywords-3-5 Data Mining, Price Estimates, Multiple Linear. 


\section{Pendahuluan}

Meningkatnya ekonomi di masyarakat semakin berkembang, dengan berbagai bisnis yang dilakukan untuk memperbaiki ekonomi rumah tangga pada masyarakat sekitar semakin berkembangnya transfortasi setiap tahun, menjadi sebuah masalah pada alat tansfortasi di era perkembangan sebelumnya, salah satunya ada dapa transfortasi kendaraan bermobil. Kini masalahnya meningkatnya jumlah produksi mobil baru dan munculnya berbagai model mobil baru berdampak dengan melimpahnya mobil bekas atau dengan sebutan mobil second. Inilah yang membuat usaha jual beli mobil bekas menjadi salah satu bisnis yang cukup menggiurkan untuk dijadikan dikalangan masyarakat. Untuk menjalankan bisnis jual beli mobil bekas dibutuhkan kecermatan dalam mengamati pergerakan harga jual beli mobil bekas yang ada dipasaran dan harus mengetahui beberapa kriteria pada mobil bekas tersebut sebelum menjualnya. Showroom Gulur motor adalah sebuah perusahaan yang bergerak dibidang jual beli mobil bekas yang berada di wilayah kota tasikmalaya. Pada umumnya harga jual mobil bekas di showroom Gulur motor ditafsirkan berdasarkan merk, harga beli, tahun keluar (tahun pembuatan atau tahun perakitan), dan kondisi mobil oleh pemilik showroom.

Mobil bekas memiliki harga jual yang menurun secara periodik, jadi harga jual suatu mobil bekas pada tahun yang sedang berjalan lebih rendah dari harga jual tahun sebelumnya dengan kota lain pasaran harga jual suatu mobil bekas yang tahun keluarnya lebih baru lebih tinggi dari tahun keluar yang lebih lama dengan catatan memiliki kondisi fisik yang sama baiknya dengan melihat sipat - sipat kecenderungan harga jual mobil bekas pada shoroom gulur motor dipengaruhi oleh parameter seperti tahun jekuar, merk, harga beli dan kondisi mobil. Maka dapat disimpulkan harga mobil bekas dapat di estimasikan sistem ini dihadapkan mampu membantu pemilik shoroom gulur motor untuk mengestimasikan harga mobil bekas tiap periodik . prediksi tersebut didasari oleh beberapa variabel yang telah ditentukan. Metode regresi linear berganda yang digunakan pada sistem ini diharapkan akan mampu melakukan estimasi harga dari jual mobil bekas berdasarkan variabel tersebut.

\section{Metode Penelitian}

Dalam menyelesaikan permasalahan ini, dilakukan tahapan-tahapan sebagai berikut sebagai penyelesaian masalah :

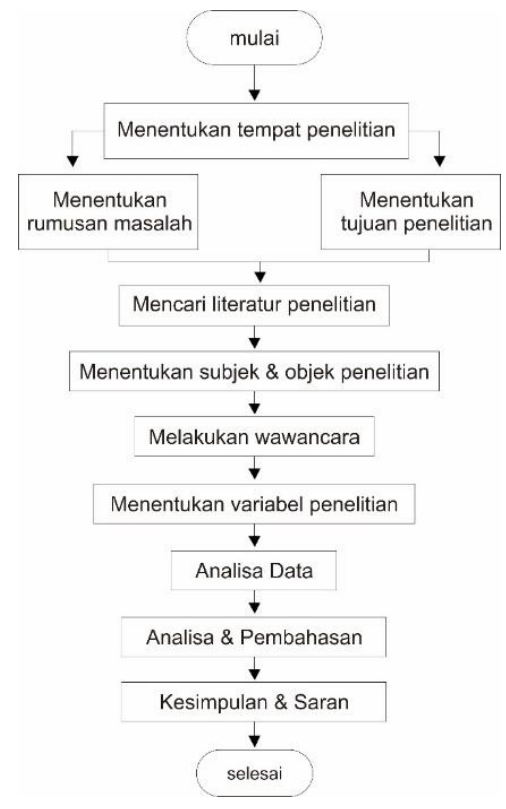

Gambar 1 Kerangka Penelitian

Pada Flow Chart diatas menggambarkan alur proses pencapaian data dan juga sampai dengan hasil dan pembahasan, yang pada mulanya kita mengolah dari sebuah data atau yang biasa kita sering tahu yaitu Data Mining 
Data mining adalah ekstraksi pola yang menarik dari data dalam jumlah besar. Dengan kata lain, data mining merupakan rangkaian proses untuk menghasilkan suatu informasi yang bernilai dari sekumpulan data yang tidak bernilai. Jadi data mining juga bisa dikatakan sebagai pengolahan data menjadi suatu informasi yang memberikan pengetahuan. [1].

Metode dalam estimasi Harga Jual Mobil bekas ini yang digunakan adalah metode Regresi Linier Berganda.Bentuk hubungan yang paling sederhana yaitu satu peubah bebas (X) dengan satu peubah tak bebas $(\mathrm{Y})$ berbentuk garis lurus atau berbentuk hubungan linier yang disebut dengan regresi linier sederhana atau sering disebut regresi linier dengan persamaan sebagai berikut:

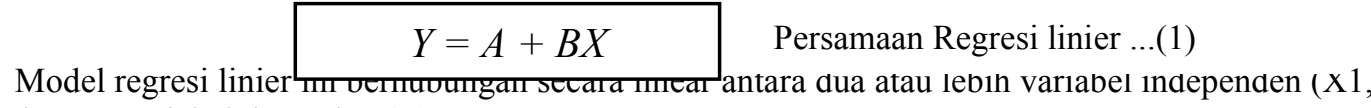
$\mathrm{X} 2, . \mathrm{Xn})$ dengan variabel dependen $(\mathrm{Y})$.

$Y t=a+B 1 . X 1+B 2 . X 2 \ldots \ldots .+B n . X n \quad$ Persamaan Regresi linier Berganda... (2)

Untuk mencari nilai konstanta dan variable regresi setiap variabel bebas dapat diperoleh dengan menggunakan matriks determinan [4]:

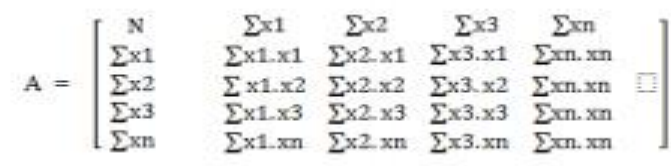

$$
\begin{aligned}
& 1 \quad \mathrm{~B}=\left[\begin{array}{l}
a \\
b 1 \\
b 2 \\
b 3 \\
b n
\end{array}\right] \\
& \mathrm{c}=\left[\begin{array}{c}
\Sigma Y \\
\Sigma Y . x 1 \\
\frac{Y}{Y Y . x 2} \\
\Sigma Y . x 3 \\
\Sigma Y . x 4
\end{array}\right] \\
& b 2=\frac{}{\operatorname{Det} A} \\
& \text { b3 }=\frac{\text { Det (A3) }}{\operatorname{Det} A} \\
& b n=\frac{\text { Det }(\mathrm{An})}{\operatorname{Det} \mathrm{A}}
\end{aligned}
$$$$
\text { ikut: }
$$

Rumus Regresi Linier Berganda :

\begin{aligned} & \hline$Y t= a+B 1 . X 1+B 2 . X 2 \ldots \ldots . .+B n . X n \\ &$\hline $\mathrm{a}=$ Konstanta \\ & $\mathrm{X} 1=$ Variabel bebas 1 \\ & $\mathrm{X} 2=$ Variabel bebas 2 \\ & $\mathrm{X} 3=$ Variabel bebas 3 \\ & $\mathrm{Xn}=$ Variabel bebas $\mathrm{n}\end{aligned}$

\section{Hasil dan Pembahasan}

Dataset penjualan mobil bekas di Showroom Gulur Motor pada tahun 2019, dengan jumlah 15 unit mobil seperti data dibawah ini :

Tabel 1 Laporan Penjualan Mobil Bekas 2019 


\begin{tabular}{|c|c|c|c|c|c|c|c|c|c|c|c|c|}
\hline Id Motor & Tipe & Tahun Keluar & Tahun Estimasi & $\mathrm{x} 1$ & $\times 2$ & $\mathrm{Y}$ & $Y_{2}$ & $\mathrm{X} 12$ & $\times 22$ & $\mathrm{X} 1 \mathrm{Y}$ & $\mathrm{X} 2 \mathrm{Y}$ & $\mathrm{X}_{1} \mathrm{X} 2$ \\
\hline 1 & innova & 2012 & 2019 & 7 & 125 & 439 & 192721 & 49 & 15625 & 3073 & 54875 & 875 \\
\hline 2 & Brio & 2014 & 2019 & 5 & 90 & 140 & 19600 & 25 & 8100 & 700 & 12600 & 450 \\
\hline 3 & Gran Livina & 2012 & 2019 & 7 & 90 & 212,6 & 45198,76 & 49 & 8100 & 1488,2 & 19134 & 630 \\
\hline 4 & Terios & 2013 & 2019 & 6 & 100 & 180,3 & 32508,09 & 36 & 10000 & 1081,8 & 18030 & 600 \\
\hline 5 & H-RV & 2016 & 2019 & 3 & 180 & 200 & 40000 & 9 & 32400 & 600 & 36000 & 540 \\
\hline 6 & Avanza & 2015 & 2019 & 4 & 105 & 130 & 16900 & 16 & 11025 & 520 & 13650 & 420 \\
\hline 7 & bmw & 2002 & 2019 & 17 & 60 & 90 & 8100 & 289 & 3600 & 1530 & 5400 & 1020 \\
\hline 8 & freed & 2012 & 2019 & 7 & 120 & 150 & 22500 & 49 & 14400 & 1050 & 18000 & 840 \\
\hline 9 & CRV & 2007 & 2019 & 12 & 145 & 180 & 32400 & 144 & 21025 & 2160 & 26100 & 1740 \\
\hline 10 & Alya & 2012 & 2019 & 7 & 60 & 95 & 9025 & 49 & 3600 & 665 & 5700 & 420 \\
\hline 11 & Xenia & 2017 & 2019 & 2 & 100 & 120 & 14400 & 4 & 10000 & 240 & 12000 & 200 \\
\hline 12 & Agya & 2015 & 2019 & 4 & 70 & 110 & 12100 & 16 & 4900 & 440 & 7700 & 280 \\
\hline 13 & Granmax & 2015 & 2019 & 4 & 105 & 130 & 16900 & 16 & 11025 & 520 & 13650 & 420 \\
\hline 14 & Jazz & 2012 & 2019 & 7 & 115 & 145 & 21025 & 49 & 13225 & 1015 & 16675 & 805 \\
\hline 15 & Panther & 2012 & 2019 & 7 & 65 & 90 & 8100 & 49 & 4225 & 630 & 5850 & 455 \\
\hline \multicolumn{4}{|c|}{ Jumlah } & 99 & 1530 & 2411,9 & 491477,85 & 849 & 171250 & 15713 & 265364 & 9695 \\
\hline
\end{tabular}

Keterangan

$\mathrm{X} 1$ : Variabel tahun keluar atau perakitan mobil ( Tahun sekarang - Tahun perakitan motor ).

X2 : Variabel harga beli mobil ( Juta Rupiah )

Y : Variabel harga jual mobil baru ( Juta Rupiah )

Penyelesaian:

1. Menentukan nilai konstanta regresi

$$
\begin{aligned}
& \sum \mathrm{x}_{1}{ }^{2} \\
& \sum \mathrm{x}_{1}{ }^{2}-\frac{\left(\sum \mathrm{x} 1\right)^{2}}{n} \\
& \sum \mathrm{x}_{2}^{2}= \\
& \sum \mathrm{x}_{2}^{2}-\frac{\left(\sum \mathrm{x} 2\right)^{2}}{n} \\
& \sum \mathrm{y}^{2}= \\
& \sum \mathrm{y}^{2}-\frac{\left(\sum \mathrm{y}\right)^{2}}{n}= \\
& \sum \mathrm{x}_{1} \mathrm{y}= \\
& \sum \mathrm{x}_{1} \mathrm{y}-\frac{\left(\sum \mathrm{x}_{1}\right) \mathrm{x}\left(\sum \mathrm{y}\right)}{n} \\
& \sum \mathrm{x}_{2} \mathrm{y}= \\
& \sum \mathrm{x}_{2} \mathrm{y}-\frac{\left(\sum \mathrm{x}_{2}\right) \mathrm{x}\left(\sum \mathrm{y}\right)}{n}=
\end{aligned}
$$

2. Menentukan nilai koefisien ( $a, b 1$, dan b2) 


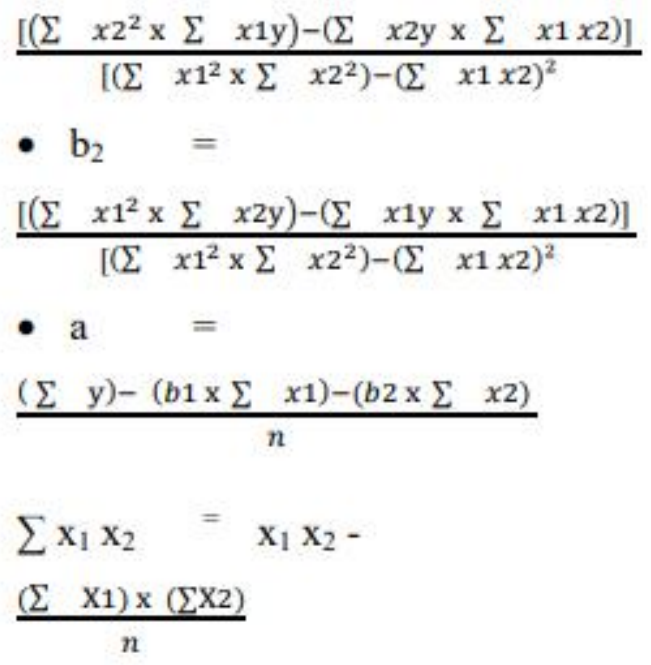

3. Memasukkan nilai koefisien (a, b1, dan b2) kedalam persamaan:

$$
\mathbf{Y}=\mathbf{a}+\mathbf{X} \mathbf{1} \mathbf{b} 1+\mathbf{X} \mathbf{2} \mathbf{b} 2 \quad \text { Persamaan Regresi linier Berganda (4) }
$$

Proses metode yaitu menu untuk menghitung mengesumlası narga juaı moır рeкаs, uengan menginputkan variabel tipe, tahun perakitan (X1), harga beli (X2), dan harga jual baru (Y). Misalkan admin menginputkan variabel sebagai berikut ;

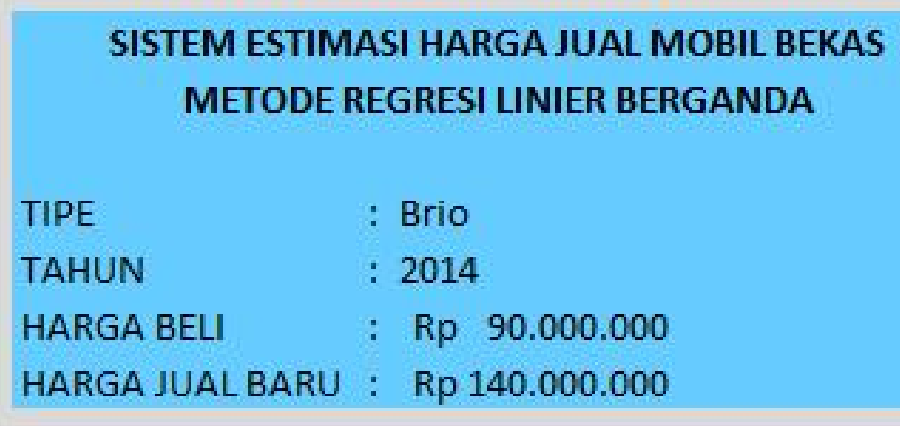

\section{Menentukan Nilai Konstanta Regresi}

$\sum X 1^{2}: 849-\left(99^{2} / 15\right)=195,6$

$\sum X 2^{2}: 171250-\left(1530^{2} / 15\right)=15190$

$\sum Y 2: 491477,85-\left(2411,9^{2} / 15\right)=103660,4093$

$\sum X 1 . Y: 15713-((99 * 2411,9) / 15)=-205,54$

$\sum X 2 . Y: 265364-((1530 * 2411,9) / 15)=19350,2$

$\sum X 1 . X 2: 9695-((99 * 1530) / 15)=-403$

\section{Menentukan Nilai Koefisian}

b1 : $((15190 \times(-205,54))-((-403) * 19350,2)) /(195,6 \times 15190)-\left((-403)^{2}\right)=1,664786712$

b2 : $((165,6 \times 19350,2)-((-403) *(-205,54))) /(195,6 \times 15190)-\left((-403)^{2}\right)=1,318045362$

a : $(2411,9 / 15)-(1,664786712 *(99 / 15))-(1,318045362 *(1530 / 15))=15,36511414$

6. Memasukan pada persamaan Linier Berganda

Persamaan yang didapati :

y : $15,36511414-(X 1 \times 1,664786712)-(X 2$ x 1,318045362)

Hasil dari Estimasi yang di dapat setelah dimasukan kedalam persamaan :

$\mathrm{y}: 15,36511414-(5 \times 1,664786712)-(90 \times 1,318045362)=112$ 
Setelah menginputkan variabel tipe, tahun perakitan (X1), harga beli (X2), dan harga jual baru (Y) dapat diketahui hasil Estimasi yang diperoleh dari persamaan Regresi Linier Berganda dari Penjualan Mobil Bekas Brio tahun 2014 adalah Rp. 112.000.000,-. Berikut hasil Estimasi pada tahun 2019 :

Tabel 2 Hasil Estimasi Mobil Bekas 2019

\begin{tabular}{|c|c|c|c|c|c|c|c|c|c|c|c|c|c|c|c|}
\hline Id Motor & Tipe & Tahun Keluar & Tahun Estimasi & $\mathrm{x} 1$ & $\mathrm{X} 2$ & $Y$ & $\mathrm{Y} 2$ & $\mathbf{x 1 2}$ & $\mathrm{x} 22$ & $\mathrm{X} 1 \mathrm{Y}$ & $\mathrm{X} 2 \mathrm{Y}$ & $\mathrm{x} 1 \times 2$ & \multicolumn{3}{|c|}{ Hasil Estimasi } \\
\hline 1 & innova & 2012 & 2019 & 7 & 125 & 439 & 192721 & 49 & 15625 & 3073 & 54875 & 875 & $\mathrm{Rp}$ & 161 & Juta \\
\hline 2 & Brio & 2014 & 2019 & 5 & 90 & 140 & 19600 & 25 & 8100 & 700 & 12600 & 450 & $\mathrm{Rp}$ & 112 & Juta \\
\hline 3 & Gran Livina & 2012 & 2019 & 7 & 90 & 212,6 & 45198,76 & 49 & 8100 & 1488,2 & 19134 & 630 & $\mathrm{Rp}$ & 115 & Juta \\
\hline 4 & Terios & 2013 & 2019 & 6 & 100 & 180,3 & 32508,09 & 36 & 10000 & 1081,8 & 18030 & 600 & $\mathrm{Rp}$ & 126 & Juta \\
\hline 5 & H-RV & 2016 & 2019 & 3 & 180 & 200 & 40000 & 9 & 32400 & 600 & 36000 & 540 & $\mathrm{Rp}$ & 227 & Juta \\
\hline 6 & Avanza & 2015 & 2019 & 4 & 105 & 130 & 16900 & 16 & 11025 & 520 & 13650 & 420 & $\mathrm{Rp}$ & 130 & Juta \\
\hline 7 & bmw & 2002 & 2019 & 17 & 60 & 90 & 8100 & 289 & 3600 & 1530 & 5400 & 1020 & $\mathrm{Rp}$ & 92 & Juta \\
\hline 8 & freed & 2012 & 2019 & 7 & 120 & 150 & 22500 & 49 & 14400 & 1050 & 18000 & 840 & $\mathrm{Rp}$ & 154 & Juta \\
\hline 9 & CRV & 2007 & 2019 & 12 & 145 & 180 & 32400 & 144 & 21025 & 2160 & 26100 & 1740 & $\mathrm{Rp}$ & 196 & Juta \\
\hline 10 & Alya & 2012 & 2019 & 7 & 60 & 95 & 9025 & 49 & 3600 & 665 & 5700 & 420 & $\mathrm{Rp}$ & 75 & Juta \\
\hline 11 & Xenia & 2017 & 2019 & 2 & 100 & 120 & 14400 & 4 & 10000 & 240 & 12000 & 200 & $\mathrm{Rp}$ & 120 & Juta \\
\hline 12 & Agya & 2015 & 2019 & 4 & 70 & 110 & 12100 & 16 & 4900 & 440 & 7700 & 280 & $\mathrm{Rp}$ & 84 & Juta \\
\hline 13 & Granmax & 2015 & 2019 & 4 & 105 & 130 & 16900 & 16 & 11025 & 520 & 13650 & 420 & $\mathrm{Rp}$ & 130 & Juta \\
\hline 14 & Jazz & 2012 & 2019 & 7 & 115 & 145 & 21025 & 49 & 13225 & 1015 & 16675 & 805 & $\mathrm{Rp}$ & 148 & Juta \\
\hline 15 & Panther & 2012 & 2019 & 7 & 65 & 90 & 8100 & 49 & 4225 & 630 & 5850 & 455 & $\mathrm{Rp}$ & 82 & Juta \\
\hline
\end{tabular}

Berikut hasil yang diperoleh dari Estimasi Mobil Bekas untuk tahun 2019 , yang telah di

Estimasi dengan metode Regresi Linier Berganda, pada tahun ini di lakukan dengan 3 variabel, tahun perakitan (X1), harga beli (X2), dan harga jual baru (Y) dapat diketahui hasil Estimasi yang diperoleh dari persamaan Regresi Linier Berganda dari Penjualan Mobil Bekas. Berikut hasil Estimasi pada tahun 2020 :

Tabel 3 Hasil Estimasi Mobil Bekas 2019

\begin{tabular}{|c|c|c|c|c|c|c|c|c|c|c|c|c|c|c|c|}
\hline Id Motor & Tipe & Tahun Keluar & Tahun Estimasi & x1 & $\mathrm{x} 2$ & $\mathbf{Y}$ & Y2 & $\mathrm{x} 12$ & $\mathrm{X} 22$ & $\mathrm{X} 1 \mathrm{Y}$ & $X 2 Y$ & x1 $x_{2} \mid$ & \multicolumn{3}{|c|}{ Hasil Estimasi } \\
\hline 1 & innova & 2012 & 2020 & 8 & 125 & 439 & 192721 & 64 & 15625 & 3512 & 54875 & \begin{tabular}{|l|}
1000 \\
\end{tabular} & $\mathrm{Rp}$ & 164 & Juta \\
\hline 2 & Brio & 2014 & 2020 & 6 & 90 & 140 & 19600 & 36 & 8100 & 840 & 12600 & 540 & $\mathrm{Rp}$ & 115 & Juta \\
\hline 3 & Gran Livina & 2012 & 2020 & 8 & 90 & 212,6 & 45198,76 & 64 & 8100 & 1700,8 & 19134 & 720 & $\mathrm{Rp}$ & 118 & Juta \\
\hline 4 & Terios & 2013 & 2020 & 7 & 100 & 180,3 & 32508,09 & 49 & 10000 & 1262,1 & 18030 & 700 & $\mathrm{Rp}$ & 130 & Juta \\
\hline 5 & H-RV & 2016 & 2020 & 4 & 180 & 200 & 40000 & 16 & 32400 & 800 & 36000 & 720 & $\mathrm{Rp}$ & 230 & Juta \\
\hline 6 & Avanza & 2015 & 2020 & 5 & 105 & 130 & 16900 & 25 & 11025 & 650 & 13650 & 525 & $\mathrm{Rp}$ & 133 & Juta \\
\hline 7 & bmw & 2002 & 2020 & 18 & 60 & 90 & 8100 & 324 & 3600 & 1620 & 5400 & 1080 & $\mathrm{Rp}$ & 95 & Juta \\
\hline 8 & freed & 2012 & 2020 & 8 & 120 & 150 & 22500 & 64 & 14400 & 1200 & 18000 & 960 & $\mathrm{Rp}$ & 158 & Juta \\
\hline 9 & CRV & 2007 & 2020 & 13 & 145 & 180 & 32400 & 169 & 21025 & 2340 & 26100 & 1885 & $\mathrm{Rp}$ & 199 & Juta \\
\hline 10 & Alya & 2012 & 2020 & 8 & 60 & 95 & 9025 & 64 & 3600 & 760 & 5700 & 480 & $\mathrm{Rp}$ & 79 & Juta \\
\hline 11 & Xenia & 2017 & 2020 & 3 & 100 & 120 & 14400 & 9 & 10000 & 360 & 12000 & 300 & $\mathrm{Rp}$ & 123 & Juta \\
\hline 12 & Agya & 2015 & 2020 & 5 & 70 & 110 & 12100 & 25 & 4900 & 550 & 7700 & 350 & $\mathrm{Rp}$ & 87 & Juta \\
\hline 13 & Granmax & 2015 & 2020 & 5 & 105 & 130 & 16900 & 25 & 11025 & 650 & 13650 & 525 & $\mathrm{Rp}$ & 133 & Juta \\
\hline 14 & Jazz & 2012 & 2020 & 8 & 115 & 145 & 21025 & 64 & 13225 & 1160 & 16675 & 920 & Rp & 151 & Juta \\
\hline 15 & Panther & 2012 & 2020 & 8 & 65 & 90 & 8100 & 64 & 4225 & 720 & 5850 & 520 & $\mathrm{Rp}$ & 85 & Juta \\
\hline
\end{tabular}

Berikut hasil yang diperoleh dari Estimasi Mobil Bekas untuk tahun 2020 , yang telah di

Estimasi dengan metode Regresi Linier Berganda. Terdapat hasil yang berbeda setelah di prediksi untuk tahun yang berbeda, pada tahun ini di lakukan dengan 3 variabel, tahun perakitan (X1), harga beli (X2), dan harga jual baru (Y) dapat diketahui hasil Estimasi yang diperoleh dari persamaan Regresi Linier Berganda dari Penjualan Mobil Bekas.

\section{Evaluasi hasil estimasi}

Berikut data hasil penjualan mobil bekas pada mobil Brio pada tahun 2019 :

Tabel 4 Hasil Penjualan Mobil Brio 2019

\begin{tabular}{|c|c|c|}
\hline ID & TYPE & HARGA JUAL \\
\hline 1 & BRIO 2014 & 118 \\
\hline 2 & BRIO 2014 & 115 \\
\hline 3 & BRIO 2014 & 109 \\
\hline 4 & BRIO 2014 & 112 \\
\hline 5 & BRIO 2014 & 130 \\
\hline 6 & BRIO 2014 & 107,5 \\
\hline 7 & BRIO 2014 & 120 \\
\hline 8 & BRIO 2014 & 110 \\
\hline 9 & BRIO 2014 & 100 \\
\hline
\end{tabular}




\begin{tabular}{|c|c|c|}
\hline ID & TYPE & HARGA JUAL \\
\hline 10 & BRIO 2014 & 125 \\
\hline \multicolumn{2}{|c|}{ RATA - RATA } & 114,65 \\
\hline
\end{tabular}

Terdapat hasil penjualan pada unit mobil Brio pada tahun 2014 di tahun 2019, terdapat hasil setelah di rata - ratakan yaitu Rp. 114.650.000,-. Berikut perbandingan antara hasil dari Estimasi dan Harga Jual yang didapatkan, pada mobil bekas Brio tahun 2014 pada tahun 2019 :

Tabel 5 Hasil Estimasi dan Penjualan Real

\begin{tabular}{|c|c|c|c|}
\hline Type & Hasil Estimasi & Real & Keterangan \\
\hline Brio 2014 & 112 & 114,65 & Naik \\
\hline
\end{tabular}

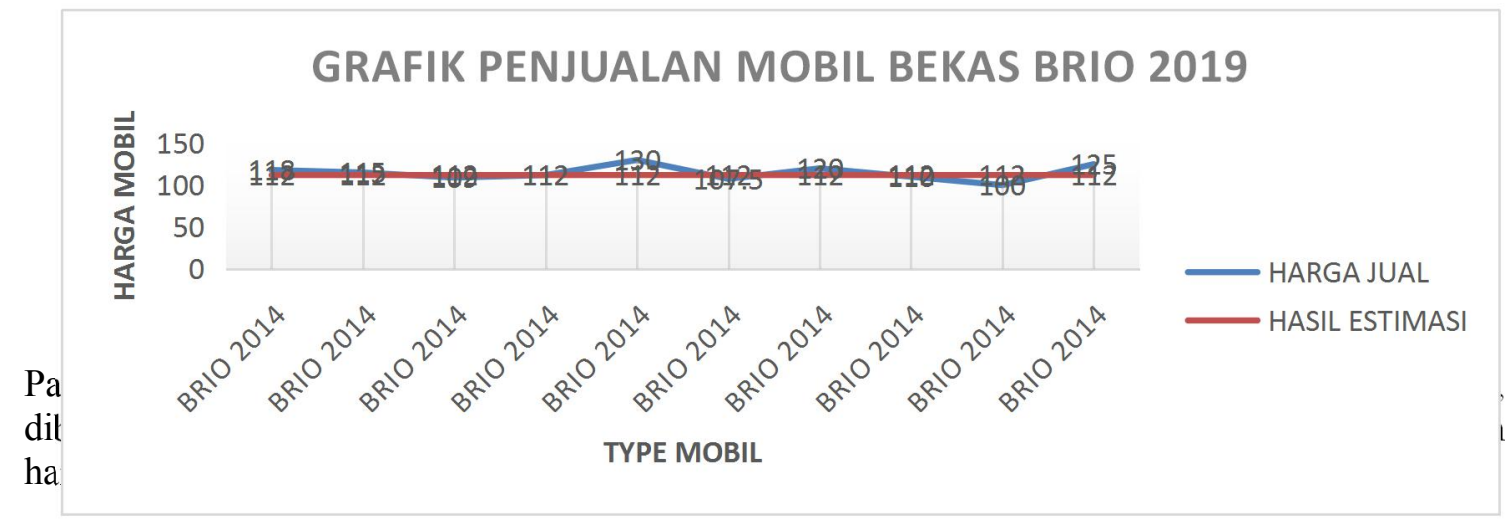

\section{Kesimpulan}

Pada hasil Estimasi Harga Mobil Bekas yang dilipih sebagai sample penelitian pada Mobil Brio 2014 menghasilkan hasil Rp. 112.000.000,-, dibandingkan dengan harga real Rp. $114,650.000$,- yang diperoleh mengalami hasil kenaikan harga dari hasil estimasi dengan harga real, sebanyak 2,65\%. Dengan mengimplementasikan metode regresi linier berganda kedalam sistem estimasi harga jual mobil bekas di Showroom Gulur Motor ini, admin dan pemilik showroom mampu mengestimasikan harga jual mobil bekas dengan variabel tahun perakitan dan variabel harga beli, dan harga jual baru kemudian akan muncul hasil estimasi. Lalu admin tidak lagi harus mencatat pembukuan secara manual, karena semua data telah terkomputerisasi didalam sistem ini.

\section{Saran}

Sistem ini menerapkan metode regresi linier berganda untuk menentukan harga mobil bekas dan masih jauh dari kesempurnaan, diharapkan penelitian ke depan dapat menggunakan metode lain serta menambahkan variabel sebagai parameter, sehingga hasil yang diperoleh semakin akurat. 


\section{Daftar Pustaka}

[1] Ilham Al Imani, 2015 SISTEM ESTIMASI HARGA JUAL MOTOR BEKAS MENGGUNAKAN METODE REGRESI LINIER BERGANDA, Jurnal Studi, Fakultas Teknik Universitas Nusantara Persatuan Guru Republik Indonesia UNP Kediri.

[2] https//www.detik.com/oto/mobil/d-3903238/beli-mobil-seken-masih-sulit-kalau-viaonline?, Rabu, 07 Maret 2018 14:30 WIB.

[3] Minarni, S.Si., 2013, PERANCANGAN APLIKASI PENJUALAN MOBIL BEKAS. Jurnal Vol 1 no.2, Fakultas Teknologi Institut Padang.

[4] Andi Maddepungeng, Irma Suryani, Awaludin Mawardani, 2016, ESTIMASI BIAYA PADA PROYEK PERUMAHAN (STUDI KASUS PROYEK PEMBANGUNAN CITRA SERANG RESIDENCE), Jurnal Fondasi Vol. 5 No. 1, Fakultas Teknik Universitas Sultan Ageung Tirtayasa.

[5] Sandy Kosasi, 2015, APLIKASI PERANCANGAN SISTEM INFORMASI PENJUALAN BERBASIS WEB DALAM MEMASARKAN MOBIL BEKAS, Jurnal Vol. 3 No. 1, STMIK Pontianak. 